\title{
IGF-I mediates regeneration of endocrine pancreas by increasing beta cell replication through cell cycle protein modulation in mice
}

\author{
J. Agudo • E. Ayuso • V. Jimenez • A. Salavert • \\ A. Casellas $\cdot$ S. Tafuro $\cdot$ V. Haurigot $\cdot$ J. Ruberte $\cdot$ \\ J. C. Segovia $•$ J. Bueren $\cdot$ F. Bosch
}

Received: 12 February 2008 / Accepted: 9 June 2008 / Published online: 29 July 2008

(C) Springer-Verlag 2008

\begin{abstract}
Aims/hypothesis Recovery from diabetes requires restoration of beta cell mass. Igfl expression in beta cells of
\end{abstract}

J. Agudo and E. Ayuso contributed equally to this work.

Electronic supplementary material The online version of this article (doi:10.1007/s00125-008-1087-8) contains supplementary material, which is available to authorised users.

J. Agudo $\cdot$ E. Ayuso $\cdot$ V. Jimenez $\cdot$ A. Salavert $\cdot$ A. Casellas $\cdot$

$\mathrm{S}$. Tafuro $\cdot$ V. Haurigot $\cdot$ J. Ruberte $\cdot$ F. Bosch $(\triangle)$

Center of Animal Biotechnology and Gene Therapy,

Edifici $\mathrm{H}$,

Universitat Autònoma de Barcelona,

08193 Bellaterra, Spain

e-mail: fatima.bosch@uab.es

J. Agudo $\cdot$ E. Ayuso $\cdot$ V. Jimenez $\cdot$ A. Salavert $\cdot$ A. Casellas $\cdot$

S. Tafuro $\cdot$ V. Haurigot $\cdot$ F. Bosch

Department of Biochemistry and Molecular Biology,

School of Veterinary Medicine,

Universitat Autònoma de Barcelona,

Bellaterra, Spain

\section{J. Ruberte}

Department of Animal Health and Anatomy, School of Veterinary

Medicine, Universitat Autònoma de Barcelona,

Bellaterra, Spain

J. Agudo $\cdot$ E. Ayuso $\cdot$ V. Jimenez $\cdot$ A. Casellas $\cdot$ S. Tafuro $\cdot$

V. Haurigot $\cdot$ J. Ruberte $\cdot$ F. Bosch

CIBER de Diabetes y Enfermedades

Metabólicas Asociadas (CIBERDEM),

Madrid, Spain

\section{J. C. Segovia $\cdot$ J. Bueren}

Hematopoiesis and Gene Therapy Division, CIEMAT,

Madrid, Spain

J. C. Segovia $\cdot$ J. Bueren

CIBER de Enfermedades Raras (CIBERER),

Madrid, Spain transgenic mice regenerates the endocrine pancreas during type 1 diabetes. However, the IGF-I-mediated mechanism(s) restoring beta cell mass are not fully understood. Here, we examined the contribution of pre-existing beta cell proliferation and transdifferentiation of progenitor cells from bone marrow in IGF-I-induced islet regeneration.

Methods Streptozotocin (STZ)-treated Igfl-expressing transgenic mice transplanted with green fluorescent protein (GFP)-expressing bone marrow cells were used. Bone marrow cell transdifferentiation and beta cell replication were measured by GFP/insulin and by the antigen identified by monoclonal antibody Ki67/insulin immunostaining of pancreatic sections respectively. Key cell cycle proteins were measured by western blot, quantitative RT-PCR and immunohistochemistry.

Results Despite elevated IGF-I production, recruitment and differentiation of bone marrow cells to beta cells was not increased either in healthy or STZ-treated transgenic mice. In contrast, after STZ treatment, IGF-I overproduction decreased beta cell apoptosis and increased beta cell replication by modulating key cell cycle proteins. Decreased nuclear levels of cyclin-dependent kinase inhibitor 1B (p27) and increased nuclear localisation of cyclin-dependent kinase (CDK)-4 were consistent with increased beta cell proliferation. However, islet expression of cyclin D1 increased only after STZ treatment. In contrast, higher levels of cyclin-dependent kinase inhibitor 1A (p21) were detected in islets from non-STZtreated transgenic mice.

Conclusions/interpretation These findings indicate that IGF-I modulates cell cycle proteins and increases replication of pre-existing beta cells after damage. Therefore, our study suggests that local production of IGF-I may be a safe approach to regenerate endocrine pancreas to reverse diabetes. 
Keywords Beta cells · Bone marrow-derived cells $\cdot$ Cell cycle $\cdot$ Islet regeneration $\cdot$ Replication

$\begin{array}{ll}\text { Abbreviations } \\ \text { AKT } & \text { protein kinase B } \\ \text { BM } & \text { bone marrow } \\ \text { CDK } & \text { cyclin-dependent kinase } \\ \text { FOXO1 } & \text { forkhead box O1 } \\ \text { GFP } & \text { green fluorescent protein } \\ \text { Ki67 } & \text { antigen identified by monoclonal antibody Ki67 } \\ \text { P- } & \text { phosphorylated } \\ \text { p21 } & \text { cyclin-dependent kinase inhibitor 1A } \\ \text { p27 } & \text { cyclin-dependent kinase inhibitor 1B } \\ \text { STZ } & \text { streptozotocin }\end{array}$

\section{Introduction}

Pancreatic beta cells are responsible for producing the insulin required to maintain glucose homeostasis. Both type 1 and 2 diabetes result from reduced beta cell mass. The mechanisms that lead to endocrine pancreas regeneration and maintenance are under extensive investigation. Regeneration of beta cell mass may arise from replication of pre-existing beta cells [1-3] or from transdifferentiation of progenitor cells from pancreatic ducts, acini or even from bone marrow (BM) [4]. Several growth factors have been identified as being able to upregulate beta cell mass $[5,6]$. We have shown that Igfl expression in beta cells of diabetic transgenic mice (1) regenerates the endocrine pancreas, probably by increasing beta cell replication and neogenesis, (2) counteracts hyperglycaemia and (3) protects islets from lymphocytic infiltration and beta cell death by apoptosis $[7,8]$. Therefore, IGF-I may be a key factor for restoring pancreatic beta cell mass during diabetes. Nevertheless, the IGF-I-mediated mechanism(s) responsible for endocrine pancreas regeneration in vivo are not fully understood.

IGF-I has the ability to recruit circulating BM cells to sites of skeletal muscle damage [9]. Likewise, IGF-I overproduction increases stem cell number and growth in ischaemic cardiac tissue, leading to an increase in myocyte turnover [10]. BM cells have also been shown to differentiate into beta cells in adult mice [4]. Injection of BM cells into diabetic recipients results in pancreatic regeneration and reduction of hyperglycaemia [11]. In contrast, other studies found little or no evidence of BM cell differentiation into beta cells in healthy pancreas or after induced damage in mice [12-14] or in non-diabetic humans [15]. Experimental conditions, such as the BM transplantation protocol, the method used for identification of cell fate and the model of pancreatic damage may account for these differences. Furthermore, it cannot be ruled out that the presence of specific (growth) factors may increase the recruitment and differentiation of $\mathrm{BM}$ cells into beta cells in islets of diabetic pancreases. Therefore, IGF-I production may contribute to endocrine pancreas regeneration through recruitment and differentiation of BM cells into functional beta cells.

Recent studies have implicated the insulin and IGF-I signalling pathways in the regulation of beta cell proliferation $[16,17]$. In the adult pancreas, pre-existing beta cell proliferation occurs at a low rate as the main mechanism of beta cell maintenance [18]. Moreover, beta cell growth matches changes in systemic insulin demand, which increases during common physiological states such as pregnancy or ageing, and also during obesity and insulin resistance [19]. Genetic lineage tracing in adult mice has shown that pre-existing beta cells are a major source of new beta cells, both in normal conditions and after partial pancreatectomy [1]. Furthermore, recent studies have revealed that adult beta cells exhibit equal proliferation potential $[2,20]$. Similarly, we have observed that streptozotocin (STZ)-treated Igfl-expressing transgenic mice presented increased BrdU incorporation in islets, suggesting increased beta cell replication [7]. In contrast, mice lacking Irs 2 and Igfl receptors show marked reduction of beta cell mass and develop diabetes [16]. Beta cell overproduction of protein kinase B (AKT) leads to beta cell proliferation and islet hyperplasia $[21,22]$. AKT can also phosphorylate the transcriptional regulator forkhead box O1 (FOXO1), leading to its nuclear exclusion. FOXO1 regulates the expression of several cell cycle components and decreased nuclear levels of FOXO1 have been shown to increase beta cell replication [23-25]. Beta cell proliferation is modulated by the interaction of a diverse set of protein components (cyclins, cyclin-dependent kinases [CDKs] and cyclin kinase inhibitors) that comprise the cell cycle molecular machinery [26]. FOXO1 regulates levels of the cyclin kinase inhibitor protein 1B (p27), while phosphorylated (P)-AKT can phosphorylate p27 and induce its nuclear exclusion [27, 28]. Therefore, IGF-I production in islets may modulate cell cycle machinery to increase beta cell replication and endocrine pancreas regeneration during diabetes.

Here, to determine the mechanisms by which IGF-I can lead to recovery of beta cell mass during diabetes, we examined the contribution of IGF-I to BM cell transdifferentiation and to proliferation of pre-existing beta cells in the pancreas of transgenic mice. While a contribution of BM cell transdifferentiation was found to be unlikely, we found that IGF-I-mediated regeneration of beta cell mass occurred predominantly by increased beta cell replication through modulation of key cell cycle proteins. 


\section{Methods}

Animals C57B16/SJL transgenic mice expressing Rip-I/Igf1 or the $\beta$-actin/Gfp chimeric genes [7, 29] were used. Male 6 -week-old green fluorescent protein (GFP)-transgenic mice were BM donors. Recipients were 2-month-old male and female wild-type and IgfI transgenic mice. For diabetes induction, mice received five intraperitoneal injections, on consecutive days, of STZ (30 or $40 \mathrm{mg} / \mathrm{kg}$ ) dissolved in $0.1 \mathrm{~mol} / \mathrm{l}$ citrate buffer ( $\mathrm{pH} 4.5$ ). Diabetes was assessed by measuring blood glucose levels using an analyser (Glucometer Elite; Bayer, Leverkusen, Germany). In all experiments, non-STZ-treated mice were sex- and age-matched with STZ-treated groups. Animal care and experimental procedures were approved by the Ethics Committee in Animal and Human Experimentation of the Universitat Autònoma de Barcelona.

Bone marrow transplantation Bone marrow was flushed from the medullary cavities of tibiae and femurs with Iscove's modified Dulbecco's medium using a 25-gauge needle. Recipient mice were irradiated using a myeloablative regimen (10 Gy fractionated in two doses, $4 \mathrm{~h}$ apart) with x-ray equipment (MG324; Philips, Hamburg, Germany) set at $300 \mathrm{kV}, 10 \mathrm{~mA}$, delivered at a dose rate of $1.03 \mathrm{~Gy} / \mathrm{min}$. After $2 \mathrm{~h}$, recipient mice received $1 \times 10^{7}$ unfractionated BM cells by tail vein injection. The level of haemopoietic chimerism was determined in peripheral blood nucleated cells by flow cytometry (Epics XL; Coulter Electronics, Hialeah, FL, USA).

Immunohistochemical and morphometrical analysis Pancreases were fixed for $24 \mathrm{~h}$ in formalin, embedded in paraffin and sectioned. Immunohistochemical detection of insulin, glucagon, IGF-I, GFP, CD45, GLUT-2, CDK4, p27, Ki67 and cyclin D1 was performed as indicated in Electronic supplementary material (ESM). Morphometrical analysis is also described in ESM.

Gene expression analysis For quantitative RT-PCR analysis, total RNA was extracted from isolated islets (ESM) using isolation reagent (Tripure; Roche Molecular Biochemicals, Mannheim, Germany) and Rneasy Mini Kit (Qiagen, Hilden, Germany). Total RNA $(1 \mu \mathrm{g})$ was reverse-transcribed for $1 \mathrm{~h}$ at $37^{\circ} \mathrm{C}$ using a kit (Omniscript Reverse transcriptase; Qiagen). Quantitative PCR was performed in SmartCycler II (Cepheid, Sunnyvale, CA, USA) using the Quantitect SYBR green kit (Qiagen). Primer sequences are shown in the ESM.

Western blot analysis Isolated islets were homogenised in protein lysis buffer. Proteins $(20-150 \mu \mathrm{g})$ were separated by
$10 \%$ SDS-PAGE (wt/vol.), transferred to polyvinylidene difluoride membranes and probed overnight at $4{ }^{\circ} \mathrm{C}$ with primary antibodies against IGF-I (R\&D Systems, Minneapolis, MN, USA), phospho-AKT, AKT, phospho-FOXO1, FOXO1 (Cell Signalling, Danvers, MA, USA), CDK4 (Santa Cruz, Palo Alto, CA, USA) and $\beta$-actin (Abcam, Cambridge, UK). Detection was performed using horseradish peroxidase-labelled anti-goat IgG or horseradish peroxidase-labelled anti-rabbit IgG (DAKO, Glostrup, Denmark) and western blotting detection reagent (ECL Plus; Amersham, Freiburg, Germany).

Statistical analysis All values are expressed as the means \pm SEM. Differences between groups were compared by Student's $t$ test. A $p$ value of less than 0.05 was considered statistically significant.

\section{Results}

Bone marrow cell transplantation in transgenic mice overexpressing Igf1 in beta cells IGF-I can participate in the recruitment of BM cells into the tissue where it is produced [9]. Therefore, the production of IGF-I by transgenic islets may increase BM cell recruitment and/or differentiation after STZ treatment. Lethally irradiated C57B16/SJL wild-type and Igfl-expressing transgenic mice were transplanted with $1 \times 10^{7} \mathrm{BM}$ cells from donor $\mathrm{Gfp}$ expressing transgenic mice [29]. ESM Fig. 1a summarises the experimental design. To examine the haemopoietic engraftment of recipient mice the proportion of GFPpositive cells in peripheral blood was determined by flow cytometry 28 days after cell transplantation. A high percentage of chimerism $(>85 \%)$ was observed in all animals 1 month after the transplant (ESM Table 1) and was maintained 4 months after transplant (data not shown). Furthermore, immunohistochemical analysis revealed that recipient lymph node cells were replaced by donor GFPproducing cells (ESM Fig. 1b). In addition, high levels of IGF-I were detected in islets from transgenic mice 4 months after transplant, indicating that expression of the transgene was not altered (ESM Fig. 1c).

Counteraction of diabetes in BM-transplanted Igf1-expressing transgenic mice At 1 month after BM transplantation, 50\% of wild-type and transgenic mice were treated with STZ $(5 \times 30 \mathrm{mg} / \mathrm{kg})$. By 30 days thereafter, wild-type mice were hyperglycaemic, while STZ-treated Igfl transgenic mice maintained normoglycaemia (Fig. 1a). This suggested that IGF-I protected beta cells against low doses of STZ. Therefore, to achieve destruction of beta cells in transgenic mice, a second treatment with higher doses of STZ $(5 \times 40 \mathrm{mg} / \mathrm{kg})$ 
a

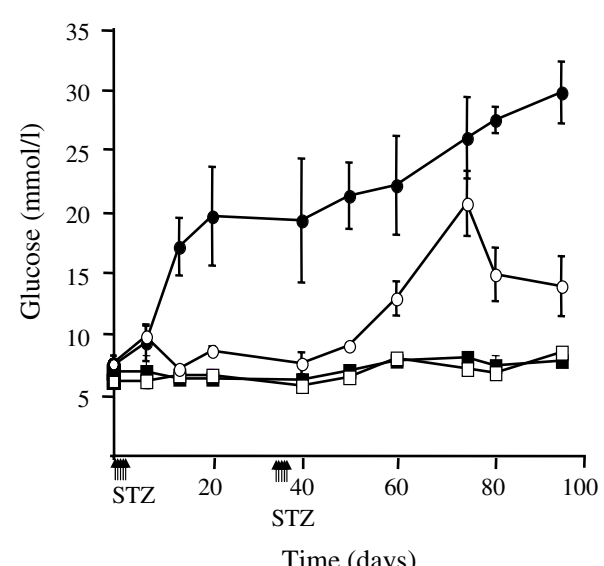

b
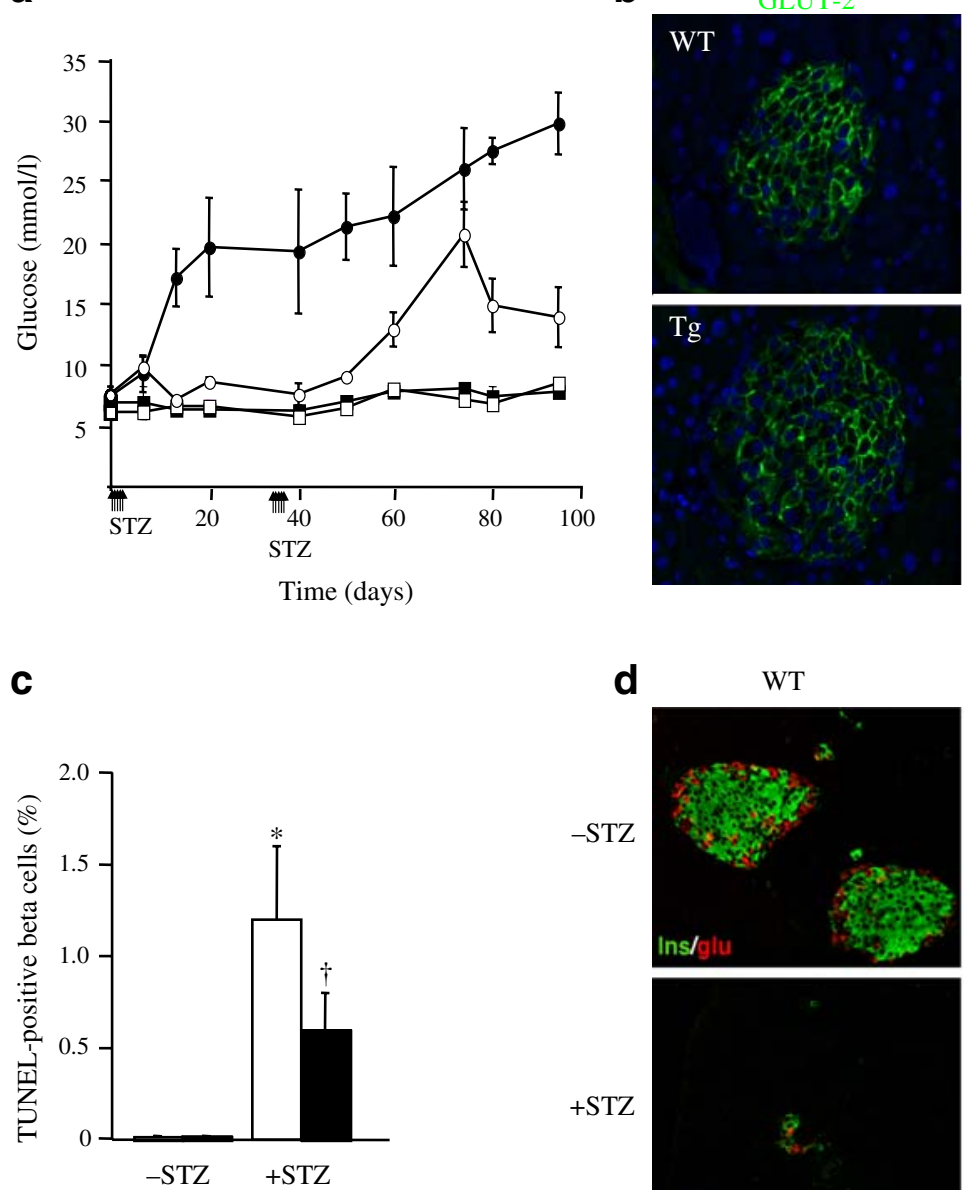

d

$-\mathrm{STZ}$
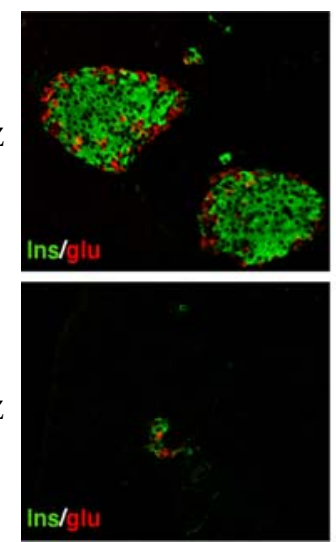

C
Ins/GLUT-2
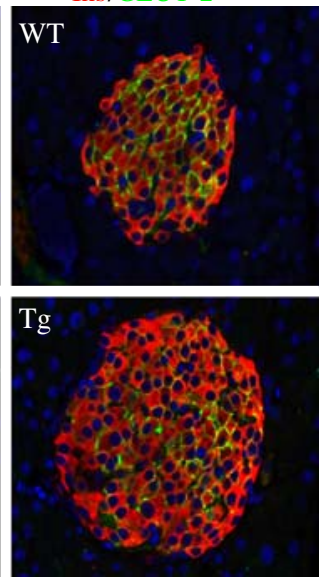

Fig. 1 Blood glucose levels, beta cell apoptosis and pancreatic islet structure after STZ treatment. a Blood glucose levels of wild-type and transgenic mice treated with or without STZ. Results are mean \pm SE $(n=4$ per group). White squares, transgenic; black squares, wild-type; white circles, STZ-transgenic; black circles, STZ-wild-type. b Immunohistochemical analysis of GLUT2 (green) and insulin (red) levels in wild-type (WT) and transgenic (Tg) islets. GLUT-2 immunostaining at the periphery of beta cells was similar between wild-type and transgenic islets. Original magnification $\times 400$. $\mathbf{c}$ Detection of apoptotic beta cells.

was administered to these animals. Blood glucose levels continued to rise in wild-type mice (over $27 \mathrm{mmol} / \mathrm{l}$ ). Transgenic mice developed hyperglycaemia (about $22 \mathrm{mmol} / \mathrm{l}$ ) by 30 days after STZ treatment. However, blood glucose levels in these animals gradually decreased thereafter, suggesting that an IGF-I-mediated regeneration process occurred in these mice (Fig. 1a), as previously reported [7]. Non-STZ-treated wildtype and transgenic mice maintained normoglycaemia during the whole study (Fig. 1a). It has been described that STZ enters the beta cell mainly through GLUT-2 [30]. Levels and localisation of GLUT-2 in beta cell plasma membrane of IgfI transgenic mice were similar to those in non-transgenic mice (Fig. 1b). These data suggest that a lack of GLUT-2 is unlikely to be responsible for the resistance to STZ in Igfl
Percentage of apoptotic beta cells was determined in wild-type and transgenic mice before and 10 days after STZ treatment. Results are mean $\pm \mathrm{SE}$ ( $n=3$ per group). ${ }^{*} p<0.05$ vs non-STZ-treated wild-type mice; $\uparrow p<0.05$ vs non-STZ-treated and STZ-treated wild-type mice. White bars, wild-type; black bars, transgenic. d Islet architecture in mice treated with $(+\mathrm{STZ})$ or without STZ $(-\mathrm{STZ})$, as shown by immunohistochemical analysis of insulin (green) and glucagon (red) expression in control and transgenic mice. Original magnification $\times 200$

transgenic mice. Thus, when islets from wild-type and transgenic mice were cultured in vitro and treated with STZ $(0.25 \mathrm{mmol} / \mathrm{l})$, a similar increase in apoptotic beta cells was observed after annexin $\mathrm{V}$ labelling and analysis by flow cytometry (ESM Fig. 2). To further determine whether IgfI transgenic mice were protected against STZ-induced damage in vivo, pancreases from 2-month-old wild-type and transgenic mice treated with STZ $(5 \times 40 \mathrm{mg} / \mathrm{kg})$ were analysed for the presence of apoptotic beta cells. At 10 days after STZ treatment, wild-type and transgenic islets showed a marked increase in apoptotic beta cells compared with non-STZtreated islets (Fig. 1c). However, a lower number of apoptotic beta cells was detected in transgenic than in wild-type islets (Fig. 1c), as observed previously [7, 8, 31]. In addition, at 

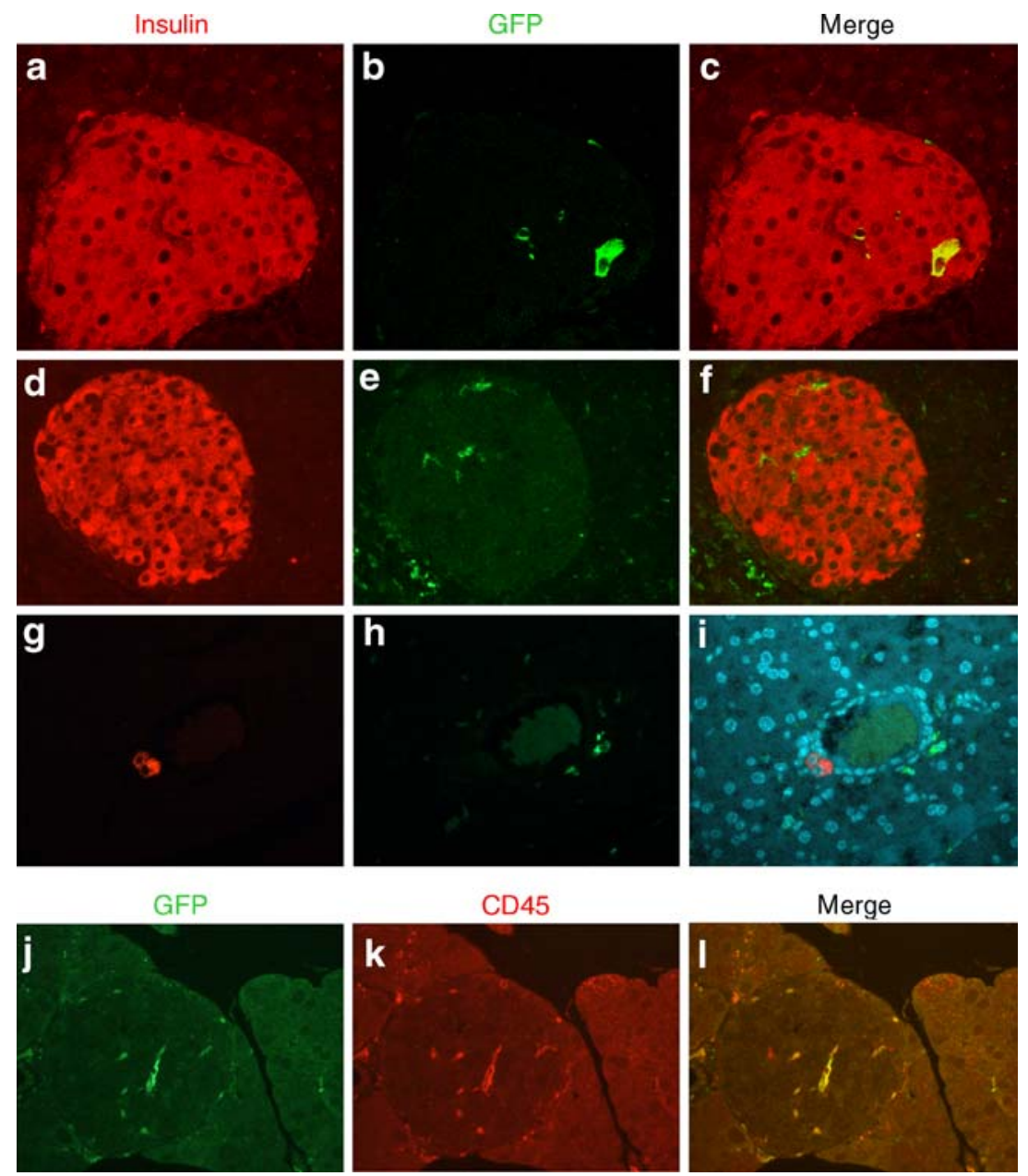

Fig. 2 Contribution of BM-derived cells to the endocrine pancreas. Representative images of $(\mathbf{a}-\mathbf{c})$ an insulin- and GFP-double-positive cell in non-STZ-treated igfl transgenic mice, (d-f) GFP-positive but insulin-negative cells inside the islets in non-STZ-treated Igfl transgenic mice and $(\mathbf{g}-\mathbf{i})$ insulin-positive but GFP-negative cells near

10 days after STZ treatment the beta cell mass in wild-type and transgenic pancreas was evaluated and a similar decrease (about 30\%) observed when compared with non-STZ-treated mice (wild-type $1.12 \pm 0.2 \mathrm{mg}$; transgenic $1.2 \pm 0.1 \mathrm{mg}$; STZwild-type $0.87 \pm 0.2 \mathrm{mg}$; STZ-transgenic $0.85 \pm 0.1$ ). These results, together with the increased apoptotic rate detected, indicated that STZ treatment induced beta cell death in transgenic islets.

Three months after STZ treatment and 4 months after the transplant, all groups of BM transplanted mice were killed. Double insulin and glucagon immunostaining of non-STZtreated wild-type and IgfI transgenic pancreas showed islets with normal distribution of insulin-expressing cells in the core and glucagon-expressing cells in the periphery (Fig. 1d). Diabetic wild-type mice showed islet destruction and lack of insulin-expressing cells. In contrast, STZtreated transgenic mice showed large islets with altered distribution of alpha and beta cells, since alpha cells no the duct in STZ-treated Igfl transgenic mice. Original magnification $\times 630(\mathbf{a}-\mathbf{c})$ and $\times 400(\mathbf{d}-\mathbf{i}) . \mathbf{j}-\mathbf{I}$ Double immunohistochemical analysis showing that GFP-positive cells were also positive for the panhaemopoietic marker CD45 in non-STZ-treated Igfl transgenic mice. Original magnification $\times 400$

longer formed a mantle around the beta cell core. These results suggested that beta cell destruction and/or regeneration may lead to disorganisation of islet cell distribution in STZ-treated transplanted transgenic mice (Fig. 1d).

Contribution of BM cells to endocrine pancreas The contribution of $\mathrm{BM}$ cells to islets of recipient mice was analysed by double GFP and insulin immunostaining. After examination of more than 900 islets in all groups of mice (wild-type and transgenic, treated and non-treated with STZ) only a total of five double GFP-positive/insulinpositive cells were detected (Fig. 2a-c, ESM Table 2). This indicated that islet production of IGF-I did not recruit BM cells for differentiation into beta cells. However, GFPpositive cells were observed inside the islets (Fig. 2d-f). When these cells were counted, no significant differences were detected between the four groups of mice (ESM Table 2), suggesting that recruitment of GFP-positive cells 
was neither dependent on Igfl expression nor on STZ treatment. In addition, we examined single insulin-positive cells $(>100$ cells) scattered in the parenchyma or located near the ducts and found no double GFP-positive/insulinpositive cells (Fig. 2g-i). Furthermore, double immunohistochemical analysis showed that GFP-positive cells in the islets also presented the CD45 marker (Fig. $2 \mathrm{j}-1$ ), indicating a haemopoietic phenotype of these cells. Therefore, no contribution of BM cells to endocrine pancreas was observed in STZ-treated transgenic mice.

IGF-I induces replication of beta cells Replication is considered to be the main mechanism for beta cell maintenance and regeneration in adult mice $[1,2]$. We next analysed whether replication of pre-existing beta cells accounted for the regenerated islets in STZ-treated IgfI transgenic mice. At 3 months after STZ treatment, islets from transgenic mice showed co-production of insulin and IGF-I in beta cells, indicating that they originated from recipient $I g f 1$ transgenic mice rather than BM cells from the donor Gfp transgenic mice (Fig. 3a). Double immunohistochemical analysis of insulin and antigen identified by monoclonal antibody $\mathrm{Ki} 67$ (Ki67) was used to identify replicating beta cells in BM-transplanted mice. A small increase, although not significant $(p=0.08)$, in replicating beta cells was observed in islets from non-STZ-treated transgenic mice (Fig. 3b). However, at 3 months after STZ treatment, a threefold increase in Ki67-positive beta cells was detected in transgenic islets (Fig. 3b). These results suggested that IGF-I production in transgenic mice increased beta cell replication after STZ-induced damage. The higher beta cell replication rate contributed to a striking increase (about fourfold) in the number of beta cells per pancreas area in STZ-treated transgenic mice compared with STZ-treated wild-type mice (Fig. 3c). This increased number of beta cells per pancreas area represented $50 \%$ of that of non-STZtreated transgenic animals and contributed to the marked improvement of hyperglycaemia in these animals compared with STZ-treated wild-type mice (Fig. 1a).

IGF-I modulates the expression of beta cell cycle proteins To investigate the mechanisms by which IGF-I induced beta cell replication, key components of the IGF-I signalling pathway and cell cycle regulation were studied in nonirradiated and non-BM-transplanted mice. When AKT was examined in Igfl-expressing islets from 2-month-old transgenic mice, a great increase in total and phosphorylated AKT (P-AKT) was observed (Fig. 4a-d). This was parallel

a
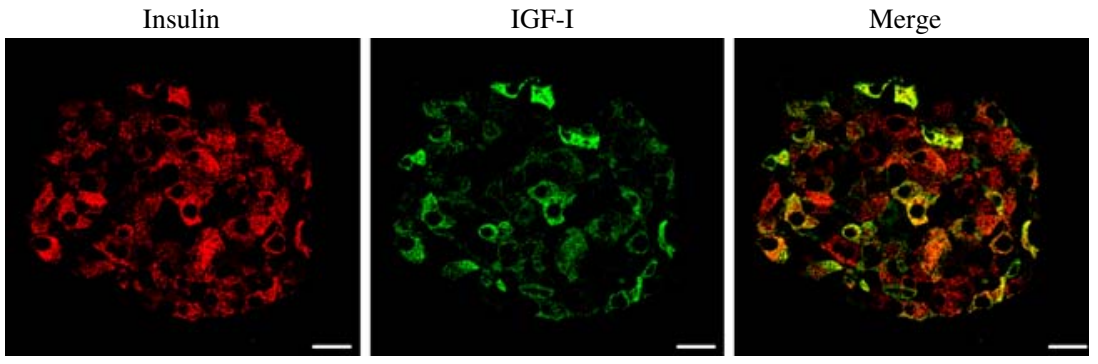

b

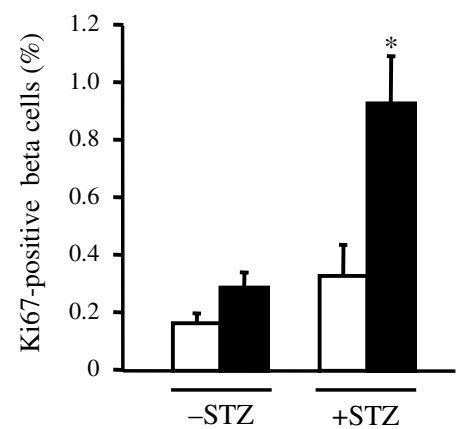

Fig. 3 IGF-I induced beta cell replication in STZ-treated transplanted transgenic mice. a Immunohistochemical analysis showing that 3 months after STZ treatment, IGF-I levels (green) were maintained in islets of transgenic mice and paralleled with the production of insulin (red). Scale bars, $17.5 \mu \mathrm{m}$. b Analysis of beta cell replication. Three pancreatic sections per animal and four animals per group were immunostained for insulin and Ki67 and the frequency of Ki67-

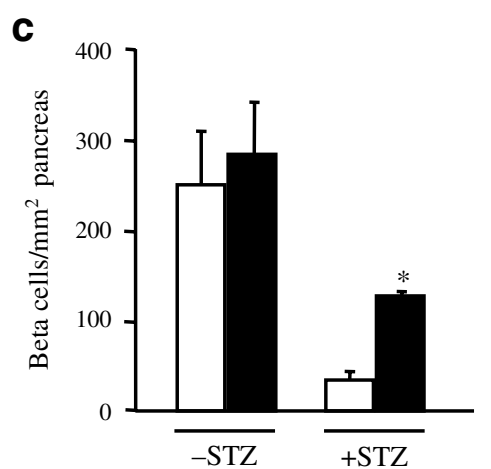

positive beta cell nuclei determined, as indicated in Methods. c The number of insulin positive cells per pancreas area was measured in pancreas sections 3 months after STZ treatment, as indicated in Methods. Results are mean \pm SE of four mice per group. ${ }^{*} p<0.05$ vs STZ-treated wild-type mice. Black bars, transgenic; white bars, wildtype 
a

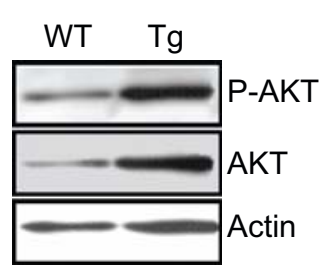

e

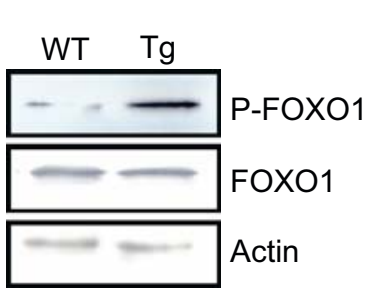

i

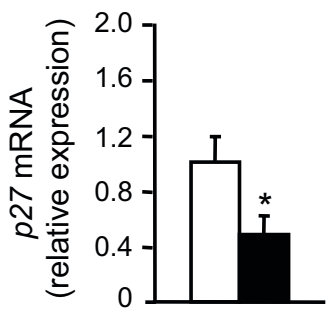

b

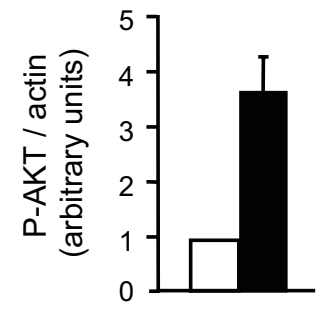

f

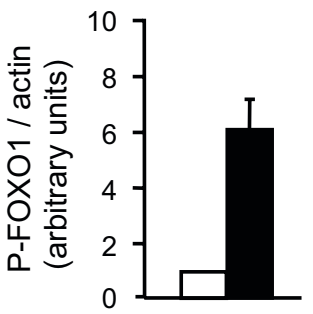

C

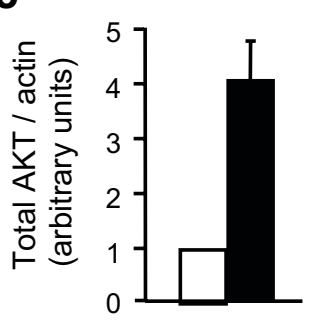

g

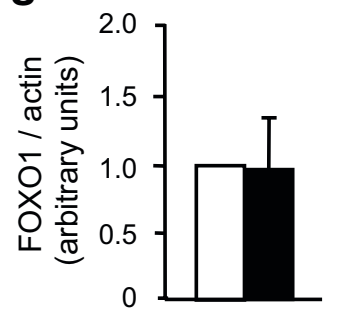

d

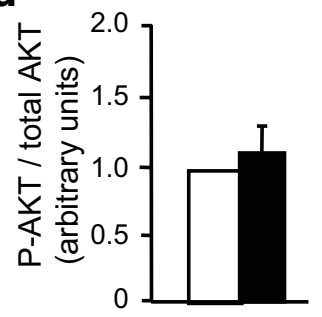

h

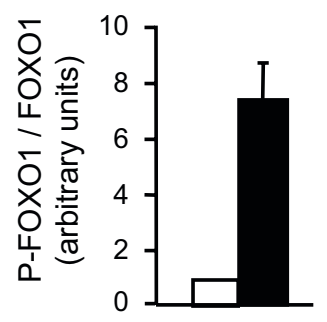

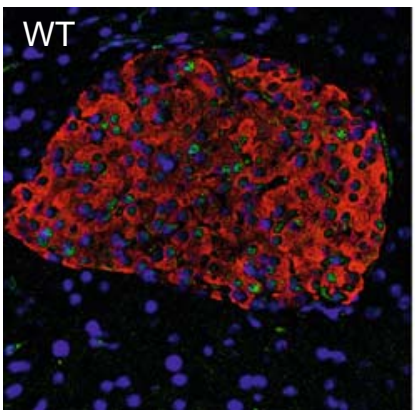

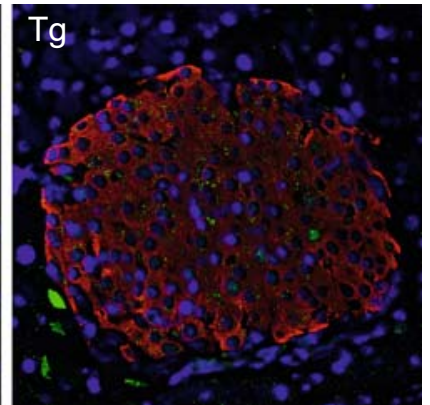

Fig. 4 Levels of AKT and FOXO1, and expression of $p 27$ in Igflexpressing transgenic islets. a-d Western blot analysis of phosphorylated (P)-AKT and total AKT using islet lysates from 2-month-old wild-type (WT) and Igfl-expressing transgenic (Tg) mice, with representative immunoblots (a) and (b-d) densitometric analysis of four different immunoblots as indicated. $\mathbf{e}-\mathbf{h}$ As above (a-d) for PFOXO1 and total FOXO1. Results $(\mathbf{b}-\mathbf{d}, \mathbf{f}-\mathbf{h})$ are mean \pm SE. Black

to an increase in the phosphorylated form of the transcription factor FOXO1 (Fig. 4e-h), suggesting that activation of IGF-I signalling led to nuclear exclusion and inactivation of FOXO1. The decrease in nuclear FOXO1 was associated with reduced expression of the cyclin kinase inhibitor $p 27$ (also known as $C d k n l b$; about $60 \%$ ) in transgenic islets (Fig. 4i). This observation, together with AKT activation, was consistent with the decreased nuclear p27 observed in Igfl-expressing islets (Fig. 4j).

The cyclin-dependent kinase 4, CDK4, a key beta cell cycle progression regulator in mice [32], needs to partner with cyclin $\mathrm{D}$ and be localised in the nucleus for activation [33]. After immunohistochemical analysis, most transgenic islets showed CDK4 in beta cell nuclei, while only few beta cells from wild-type islets showed nuclear CDK4 (Fig. 5a). After western blot analysis, an increase (about twofold) in CDK4 protein levels was noted in transgenic islets (Fig. 5b, bars, transgenic; white bars, wild-type. i The expression of $p 27$ gene was measured by quantitative PCR analysis of total RNA from isolated islets, as indicated in Methods. Results are means $\pm \mathrm{SE}$ of four pools of islets from three mice per pool. j Immunohistochemical analysis showing that $\mathrm{p} 27$ protein (green) was significantly reduced in the nuclei of transgenic beta cells (red). Original magnification $\times 400$. Blue, nuclei

c), which would be able to increase CDK4 activation. Therefore, these results were consistent with activation of cell cycle progression in Igfl-expressing islets.

Cyclin D1 or D2 partners with CDK4 to induce beta cell proliferation [26, 34]. At 2 months of age, C57B16/SJL transgenic mice do not show islet hyperplasia [7]. Moreover, pancreas from 2-month-old wild-type and transgenic mice showed similar percentages of Ki67-positive cells (wildtype $0.65 \pm 0.07 \%$ vs transgenic $0.68 \pm 0.05 \%$ ). Although an increase in nuclear CDK4 was observed in transgenic islets, no increase in the expression of either cyclin D1 or D2 was observed (Fig. 6a, b). This was consistent with a low rate of beta cell proliferation in healthy transgenic mice. However, 10 days after STZ treatment $(5 \times 40 \mathrm{mg} / \mathrm{kg})$, an approximately 2.5 -fold increase in cyclin D1 expression was noted in transgenic islets, while cyclin D2 expression remained unchanged (Fig. 6a, b). Furthermore, an increased number 
a

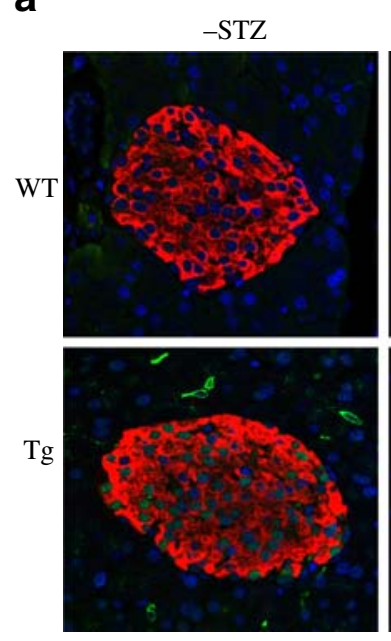

b

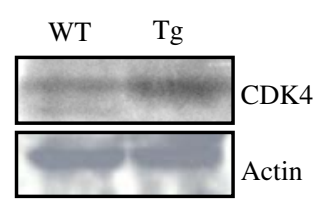

+ STZ

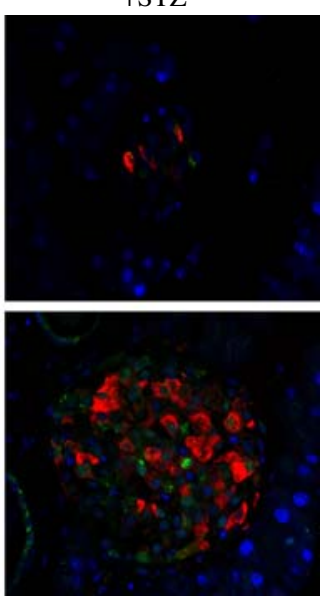

C

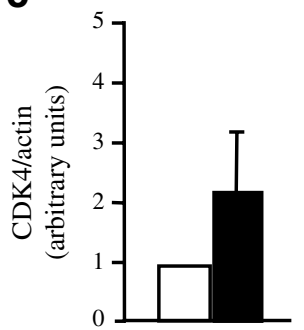

Fig. 5 Analysis of CDK4 protein in pancreatic islets. a Double immunostaining of pancreatic sections with CDK4 (green) and insulin (red). Beta cells from transgenic mice accumulated CDK4 in the nucleus. Representative immunohistochemical analysis of pancreas from 2-month-old healthy (-STZ) and STZ-treated (10 days) (+STZ) mice are shown. Original magnification $\times 630$. Blue, nuclei; $\mathrm{Tg}$, transgenic; WT, wild-type. b, c Western blot analysis of CDK4 using islet lysates from 2-month-old wild-type and IGF-I-expressing transgenic mice, with (b) a representative immunoblot and (c) densitometric analysis of three different immunoblots, as indicated in Methods. Results are mean \pm SE. Black bars, transgenic; white bars, wild-type

of insulin-positive cells with cyclin D1-positive nuclei was observed in islets from STZ-treated transgenic compared with STZ-treated wild-type mice (STZ-transgenic $66 \pm 10 \%$ vs STZ-wild-type $40 \pm 4 \%, p<0.05$; Fig. $6 c$ ). CDK 4 was also present in the nuclei of Igfl transgenic mice after STZ treatment (Fig. 5a). Furthermore, the expression of the cell cycle inhibitory protein $p 21$ (also known as $C d k n 1 a$ ) was increased (about threefold) in islets from healthy transgenic mice, while it remained unchanged in islets from STZtreated transgenic mice (Fig. 6d). These results suggest that IGF-I mainly increased beta cell proliferation through activation of the cyclin D1/CDK4 complex after islet damage.

\section{Discussion}

Transgenic mice expressing IGF-I in islets regenerate the endocrine pancreas after STZ-induced damage, which

suggests that this growth factor may be key in restoring beta cell mass when expressed in the pancreas during diabetes [7, 8]. Defining the mechanisms by which IGF-I regulates the proliferation of pancreatic beta cells is an essential prerequisite for the design of new strategies to regenerate this cell population. IGF-I-mediated effects in pancreas regeneration may be direct, by acting on and inducing replication of remaining beta cells, and/or indirect, by acting in cell types other than beta cells, which in turn may differentiate into beta cells.

IGF-I has been shown to increase recruitment of BM cells to sites of skeletal and cardiac muscle damage to enhance regeneration $[9,35]$. We observed that healthy wild-type and Igfl transgenic-transplanted mice showed GFP-positive cells in the interstitium of the endocrine pancreas. However, after analysis of more than 10,000 beta cells, only one cell was found expressing both GFP and insulin (less than $0.01 \%$ ), indicating that no significant differentiation of BM cells into beta cells occurred in transgenic healthy animals. Thus, IGF-I production in islets did not increase BM cell transdifferentiation. In contrast, it has been reported that about $1.7 \%$ to $3 \%$ of $\mathrm{BM}$ cells transdifferentiate into beta cells at 4 to 6 weeks after transplantation [4]. However, other studies have also reported little or no $\mathrm{BM}$ cell differentiation to beta cells [12-14, 36, 37].

The ability of BM cells to differentiate into other cell types may be dependent on tissue-specific damage $[9,38]$. Several reports indicate that STZ treatment of BM-transplanted mice did not increase BM cell transdifferentiation into beta cells and mice developed hyperglycaemia [1214]. Similarly, we found a strong reduction in the beta cell mass and no GFP-positive/insulin-positive cells in diabetic wild-type mice. In all these studies, BM cells were transplanted prior to STZ treatment, indicating that STZinduced damage did not mobilise BM cells to the pancreas. In contrast, injection of c-Kit-positive BM cells into already diabetic mice reduced hyperglycaemia [11]. Amelioration of glycaemia was not due to BM cell transdifferentiation into beta cells, but rather to the BM cell capacity to initiate pancreatic tissue regeneration [11]. Since only one GFPpositive/insulin-positive cell was detected, we conclude that BM cells do not contribute to endocrine pancreas regeneration in diabetic Igfl transgenic mice and suggest that BM cell differentiation into beta cells in vivo is a rare event. Our results clearly contrast with studies performed in injured skeletal and cardiac muscles, in which IGF-I increased BM cell recruitment $[9,10,35]$.

When transplanted mice were treated with low doses of STZ $(5 \times 30 \mathrm{mg} / \mathrm{kg})$, wild-type mice developed hyperglycaemia, while transgenic mice were normoglycaemic. The second administration of a higher dose of STZ (5 $\times$ $40 \mathrm{mg} / \mathrm{kg}$ ) to the transgenic mice led to a progressive 
Fig. 6 Expression of cyclin D1 and D2 and $p 21$ in $I g f 1-$ expressing transgenic islets. Cyclin D1 (a) and D2 (b) expression was determined by quantitative PCR analysis of total RNA from isolated islets from 2-month-old healthy mice (-STZ) and 10 days after STZtreatment, as indicated in the Methods. Results are means \pm SE of four pools of islets from three mice per pool. ${ }^{*} p<0.05$ vs nonSTZ-treated wild-type and STZtreated wild-type mice. c Double immunostaining of pancreatic sections with cyclin D1 (green) and insulin (red). Original magnification $\times 630$. Blue, nuclei; $\mathrm{Tg}$, transgenic; WT, wild-type. d The expression of $p 21$ gene was measured by quantitative PCR analysis of total RNA from isolated islets, as indicated in the Methods. Results are means \pm SE of four pools of islets from three mice per pool. ${ }^{*} p<0.05$ vs nonSTZ-treated wild-type mice. Black bars, transgenic; white bars, wild-type a

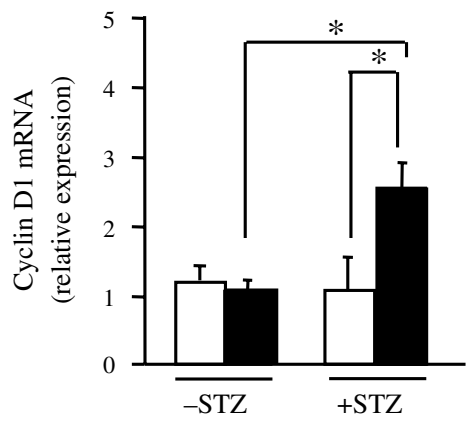

C
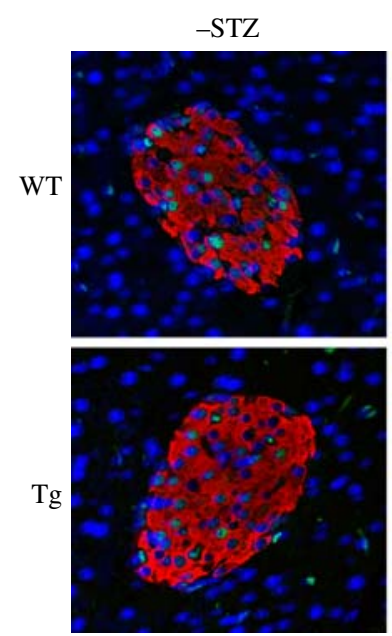

b

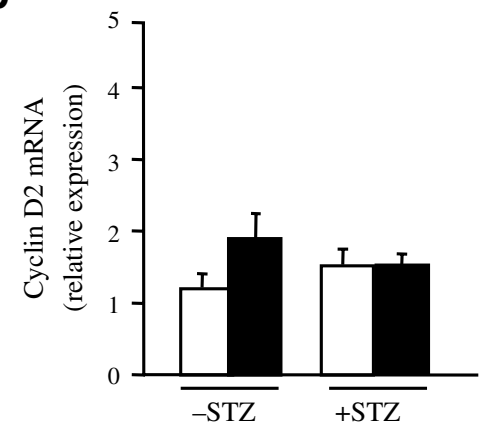

d

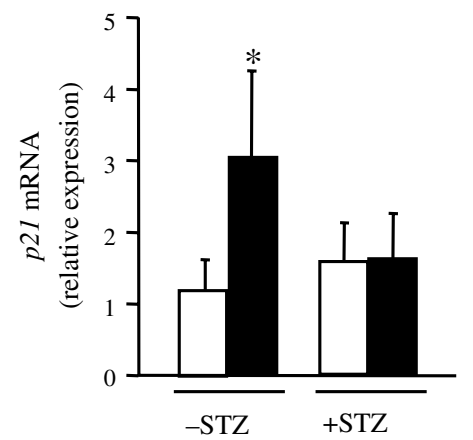

increase in glycaemia, which subsequently and gradually decreased. This suggested that IGF-I production partially protected islets from destruction. Thus, 10 days after STZ treatment, an increase in apoptotic beta cells was detected in Igfl-expressing islets, which was lower than that in wildtype islets. Alternatively and/or concomitantly, an IGF-Imediated increase in beta cell replication may have contributed to prevention of hyperglycaemia in STZ-treated transplanted transgenic mice. This was consistent with higher Ki67-positive/insulin-positive cell number in islets of transgenic mice even at 3 months after STZ treatment. Thus, our results suggest that IGF-I-mediated proliferation of pre-existing beta cells and decreased apoptosis could increase beta cell mass and reduce hyperglycaemia.

Increased P-AKT levels in transgenic islets indicated activation of the IGF-I receptor signalling pathway. Similarly, active AKT overproduction in beta cells leads to higher proliferation rate and islet hyperplasia [21, 22]. Consistent with AKT activation, Igfl-expressing islets exhibited increased FOXO1 phosphorylation. In addition to downregulating $p 27$ expression by direct phosphorylation of FOXO1, AKT also promotes nuclear exclusion of p27 by direct phosphorylation [27]. Consistent with increased P-AKT and P-FOXO1, a decrease in the expres- sion and nuclear immunolocalisation of p27 in Igflexpressing islets was also observed. The protein p27 inactivates CDK4 and blocks beta cell proliferation, and both CDK4 null mice and transgenic mice overexpressing p27 in beta cells show greatly reduced beta cell mass and diabetes [32, 39]. Nuclear localisation of CDK4 was observed in beta cells of transgenic islets, both before and after STZ treatment. However, non-STZ-treated Igfl transgenic mice did not present uncontrolled beta cell proliferation, suggesting that the increase in CDK4 induced by IGF-I is not sufficient to enhance replication. In agreement with these results, we did not detect a significant increase in Ki67-positive beta cells in the pancreas of either 2-monthold or 6-month-old Igfl-expressing transgenic mice compared with wild-type mice.

CDK4 partners with D-cyclins for activation [33]. It has been reported that cyclin D2 is expressed at higher levels than cyclin D1 and is crucial for controlling postnatal beta cell expansion [40]. Igfl-expressing islets showed similar cyclin D1 and D2 levels to wild-type, suggesting that levels of these cyclins were probably too low to increase CDK4 activity. However, after STZ treatment an increase in the expression of cyclin D1 in transgenic islets was observed, which probably increased beta cell proliferation. It has been 
suggested that cyclin D1 plays a critical accessory role to cyclin D2 to partner with CDK4 and promote beta cell duplication [41]. Similarly, transgenic mice overexpressing Igfl in skeletal muscle showed regeneration and increased levels of cyclin D1 only after tissue damage [42]. In this regard, overexpression of cyclin D1 increased beta cell replication in vitro [43] and in vivo [44]. Furthermore, increased beta cell replication by glucagon-like peptide-1 involves transcriptional induction of cyclin D1 [45]. Parallel to increased cyclin D1, a normalisation of $p 21$ expression in STZ-treated IgfI transgenic islets compared with wild-type islets was observed. It has been postulated that p21 may inhibit beta cell growth by acting as a molecular 'brake' on beta cell cycle progression [46]. In islets from non-STZ-treated transgenic mice, we found increased expression of $p 21$, which was not detected after STZ treatment. This finding suggests that IGF-I may increase beta cell replication predominantly under stress conditions that lead to beta cell destruction. These results are also consistent with the fact that no over-regeneration has ever been detected in STZ-treated Igfl-expressing transgenic mice after normalisation of glycaemia [7, 8]. In addition, normoglycaemic regenerated STZ-treated transgenic mice show normal glucose tolerance (data not shown; [7]), indicating that these mice maintain physiological glucose homeostasis. These findings also agree with the fact that Igfl-expressing transgenic mice did not develop tumours.

In summary, this study demonstrates that IGF-I-mediated beta cell mass regeneration during diabetes was not dependent on BM cell transdifferentiation. In contrast, we show that IgfI expression increased beta cell replication and decreased beta cell apoptosis. This study agrees with genetic lineage tracing studies demonstrating that beta cell self-duplication is the major source of new beta cells during adult life in mice [1, 47]. Furthermore, adult beta cells exhibit equal proliferation potential and expand from within a vast and seemingly uniform pool of mature beta cells $[2$, 20]. Since local IGF-I production is safe and does not lead to over-regeneration, this study supports the notion that IgfI gene transfer to the pancreas in vivo to induce beta cell replication and prevent beta cell apoptosis may be key for reversal of type 1 and 2 diabetes. However, rodents have a much higher capacity for beta cell replication than humans [19]. Although it is not clear to what extent beta cell replication contributes to the maintenance of beta cell mass in adult humans, a 100-fold increase in the frequency of beta cell proliferation has been reported in an 89-year-old man with recent-onset type 1 diabetes [48]. Furthermore, IGF-I production prevents islet lymphocytic infiltration and decreases beta cell apoptosis [7, 8], which could overcome the increased vulnerability to apoptosis of replicating beta cells described in type 1 and 2 diabetes [19]. Recently, progress has been achieved in genetic manipulation of mouse and diabetic dog pancreas in vivo $[49,50]$. Thus, new gene therapy approaches for diabetes focused on endocrine pancreas regeneration may be envisaged in the future.

Acknowledgements We thank M. Watford and C. J. Mann for helpful discussions. J. Agudo and V. Jimenez were recipients of predoctoral fellowships from Ministerio de Educación, Cultura y Deporte, Spain. E. Ayuso and A. Salavert were recipients of predoctoral fellowships from Direcció General de Recerca, Generalitat de Catalunya. This work was supported by grants from Plan Nacional I + D + I (SAF2005-02381), Instituto de Salud Carlos III (CIBER de Diabetes y Enfermedades Metabólicas Asociadas), Spain, and from the European Community (BetaCellTherapy, FP6-2004-512145).

Duality of interest The authors declare that there is no duality of interest associated with this manuscript.

\section{References}

1. Dor Y, Brown J, Martinez OI, Melton DA (2004) Adult pancreatic beta-cells are formed by self-duplication rather than stem-cell differentiation. Nature 429:41-46

2. Teta M, Rankin MM, Long SY, Stein GM, Kushner JA (2007) Growth and regeneration of adult beta cells does not involve specialized progenitors. Dev Cell 12:817-826

3. Nir T, Melton DA, Dor Y (2007) Recovery from diabetes in mice by beta cell regeneration. J Clin Invest 117:2553-2561

4. Ianus A, Holz GG, Theise ND, Hussain MA (2003) In vivo derivation of glucose-competent pancreatic endocrine cells from bone marrow without evidence of cell fusion. J Clin Invest 111:843-850

5. Bonner-Weir S, Weir GC (2005) New sources of pancreatic betacells. Nat Biotechnol 23:857-861

6. Halban PA (2004) Cellular sources of new pancreatic beta cells and therapeutic implications for regenerative medicine. Nat Cell Biol 6:1021-1025

7. George M, Ayuso E, Casellas A, Costa C, Devedjian JC, Bosch F (2002) Beta cell expression of IGF-I leads to recovery from type 1 diabetes. J Clin Invest 109:1153-1163

8. Casellas A, Salavert A, Agudo J et al (2006) Expression of IGF-I in pancreatic islets prevents lymphocytic infiltration and protects mice from type 1 diabetes. Diabetes 55:3246-3255

9. Musaro A, Giacinti C, Borsellino G et al (2004) Stem cellmediated muscle regeneration is enhanced by local isoform of insulin-like growth factor 1. Proc Natl Acad Sci U S A 101:12061210

10. Torella D, Rota M, Nurzynska D et al (2004) Cardiac stem cell and myocyte aging, heart failure, and insulin-like growth factor-1 overexpression. Circ Res 94:514-524

11. Hess D, Li L, Martin M et al (2003) Bone marrow-derived stem cells initiate pancreatic regeneration. Nat Biotechnol 21:763-770

12. Taneera J, Rosengren A, Renstrom E et al (2006) Failure of transplanted bone marrow cells to adopt a pancreatic beta-cell fate. Diabetes 55:290-296

13. Lechner A, Yang YG, Blacken RA, Wang L, Nolan AL, Habener JF (2004) No evidence for significant transdifferentiation of bone marrow into pancreatic beta-cells in vivo. Diabetes 53:616-623

14. Choi JB, Uchino H, Azuma K et al (2003) Little evidence of transdifferentiation of bone marrow-derived cells into pancreatic beta cells. Diabetologia 46:1366-1374

15. Butler AE, Huang A, Rao PN et al (2007) Hematopoietic stem cells derived from adult donors are not a source of pancreatic betacells in adult nondiabetic humans. Diabetes 56:1810-1816 
16. Withers DJ, Burks DJ, Towery HH, Altamuro SL, Flint CL, White MF (1999) Irs-2 coordinates Igf-1 receptor-mediated beta-cell development and peripheral insulin signalling. Nat Genet 23:32-40

17. Uchida T, Nakamura T, Hashimoto $N$ et al (2005) Deletion of Cdkn1b ameliorates hyperglycemia by maintaining compensatory hyperinsulinemia in diabetic mice. Nat Med 11:175-182

18. Ackermann AM, Gannon M (2007) Molecular regulation of pancreatic beta-cell mass development, maintenance, and expansion. J Mol Endocrinol 38:193-206

19. Butler PC, Meier JJ, Butler AE, Bhushan A (2007) The replication of beta cells in normal physiology, in disease and for therapy. Nat Clin Pract Endocrinol Metab 3:758-768

20. Brennand K, Huangfu D, Melton D (2007) All beta cells contribute equally to islet growth and maintenance. PLoS Biol 5:e163

21. Bernal-Mizrachi E, Wen W, Stahlhut S, Welling CM, Permutt MA (2001) Islet beta cell expression of constitutively active Akt1/PKB alpha induces striking hypertrophy, hyperplasia, and hyperinsulinemia. J Clin Invest 108:1631-1638

22. Tuttle RL, Gill NS, Pugh W et al (2001) Regulation of pancreatic beta-cell growth and survival by the serine/threonine protein kinase Akt1/PKBalpha. Nat Med 7:1133-1137

23. Brunet A, Bonni A, Zigmond MJ et al (1999) Akt promotes cell survival by phosphorylating and inhibiting a Forkhead transcription factor. Cell 96:857-868

24. Accili D, Arden KC (2004) FoxOs at the crossroads of cellular metabolism, differentiation, and transformation. Cell 117:421-426

25. Okamoto H, Hribal ML, Lin HV, Bennett WR, Ward A, Accili D (2006) Role of the forkhead protein FoxO1 in beta cell compensation to insulin resistance. J Clin Invest 116:775-782

26. Cozar-Castellano I, Fiaschi-Taesch N, Bigatel TA et al (2006) Molecular control of cell cycle progression in the pancreatic betacell. Endocr Rev 27:356-370

27. Shin I, Yakes FM, Rojo F et al (2002) PKB/Akt mediates cell-cycle progression by phosphorylation of p27(Kip1) at threonine 157 and modulation of its cellular localization. Nat Med 8:1145-1152

28. Viglietto G, Motti ML, Bruni P et al (2002) Cytoplasmic relocalization and inhibition of the cyclin-dependent kinase inhibitor p27 (Kip1) by PKB/Akt-mediated phosphorylation in breast cancer. Nat Med 8:1136-1144

29. Okabe M, Ikawa M, Kominami K, Nakanishi T, Nishimune Y (1997) 'Green mice' as a source of ubiquitous green cells. FEBS Lett 407:313-319

30. Wang Z, Gleichmann H (1998) GLUT2 in pancreatic islets: crucial target molecule in diabetes induced with multiple low doses of streptozotocin in mice. Diabetes 47:50-56

31. Robertson K, Lu Y, De Jesus K et al (2008) A general and islet cell-enriched overexpression of IGF-I results in normal islet cell growth, hypoglycemia and significant resistance to experimental diabetes. Am J Physiol Endocrinol Metab 294:E928-E938

32. Rane SG, Dubus P, Mettus RV et al (1999) Loss of Cdk4 expression causes insulin-deficient diabetes and $\mathrm{Cdk} 4$ activation results in beta-islet cell hyperplasia. Nat Genet 22:44-52

33. Malumbres M, Barbacid M (2005) Mammalian cyclin-dependent kinases. Trends Biochem Sci 30:630-641

34. Heit JJ, Karnik SK, Kim SK (2006) Intrinsic regulators of pancreatic beta-cell proliferation. Annu Rev Cell Dev Biol 22:311-338
35. Mourkioti F, Rosenthal N (2005) IGF-1, inflammation and stem cells: interactions during muscle regeneration. Trends Immunol 26:535-542

36. Mathews V, Hanson PT, Ford E, Fujita J, Polonsky KS, Graubert TA (2004) Recruitment of bone marrow-derived endothelial cells to sites of pancreatic beta-cell injury. Diabetes 53:91-98

37. Urban VS, Kiss J, Kovacs J et al (2008) Mesenchymal stem cells cooperate with bone marrow cells in therapy of diabetes. Stem Cells 26:244-253

38. Quintana-Bustamante O, Alvarez-Barrientos A, Kofman AV et al (2006) Hematopoietic mobilization in mice increases the presence of bone marrow-derived hepatocytes via in vivo cell fusion. Hepatology 43:108-116

39. Rachdi L, Balcazar N, Elghazi L et al (2006) Differential effects of p27 in regulation of beta-cell mass during development, neonatal period, and adult life. Diabetes 55:3520-3528

40. Kushner JA, Ciemerych MA, Sicinska E et al (2005) Cyclins D2 and D1 are essential for postnatal pancreatic beta-cell growth. Mol Cell Biol 25:3752-3762

41. Kushner JA (2006) Beta-cell growth: an unusual paradigm of organogenesis that is cyclin D2/Cdk4 dependent. Cell Cycle 5:234 237

42. Rabinovsky ED, Gelir E, Gelir S et al (2003) Targeted expression of IGF-1 transgene to skeletal muscle accelerates muscle and motor neuron regeneration. FASEB J 17:53-55

43. Cozar-Castellano I, Takane KK, Bottino R, Balamurugan AN, Stewart AF (2004) Induction of beta-cell proliferation and retinoblastoma protein phosphorylation in rat and human islets using adenovirus-mediated transfer of cyclin-dependent kinase-4 and cyclin D1. Diabetes 53:149-159

44. Zhang X, Gaspard JP, Mizukami Y, Li J, Graeme-Cook F, Chung DC (2005) Overexpression of cyclin D1 in pancreatic beta-cells in vivo results in islet hyperplasia without hypoglycemia. Diabetes 54:712-719

45. Friedrichsen BN, Neubauer N, Lee YC et al (2006) Stimulation of pancreatic beta-cell replication by incretins involves transcriptional induction of cyclin D1 via multiple signalling pathways. J Endocrinol 188:481-492

46. Cozar-Castellano I, Weinstock M, Haught M, Velazquez-Garcia S, Sipula D, Stewart AF (2006) Evaluation of beta-cell replication in mice transgenic for hepatocyte growth factor and placental lactogen: comprehensive characterization of the G1/S regulatory proteins reveals unique involvement of p21cip. Diabetes 55:70 77

47. Georgia S, Bhushan A (2004) Beta cell replication is the primary mechanism for maintaining postnatal beta cell mass. J Clin Invest 114:963-968

48. Meier JJ, Lin JC, Butler AE, Galasso R, Martinez DS, Butler PC (2006) Direct evidence of attempted beta cell regeneration in an 89 -year-old patient with recent-onset type 1 diabetes. Diabetologia 49:1838-1844

49. Ayuso E, Chillon M, Agudo J et al (2004) In vivo gene transfer to pancreatic beta cells by systemic delivery of adenoviral vectors. Hum Gene Ther 15:805-812

50. Ayuso E, Chillon M, Garcia F et al (2006) In vivo gene transfer to healthy and diabetic canine pancreas. Mol Ther 13:747-755 